Epidemiology and Infection

http://journals.cambridge.org/HYG

EPIDEMIOLOGY \&

INFECTION

Additional services for Epidemiology and Infection:

Email alerts: Click here

Subscriptions: Click here

Commercial reprints: Click here

Terms of use : $\underline{\text { Click here }}$

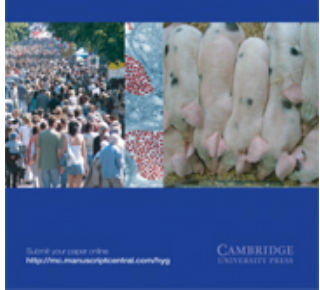

\title{
Feasibility of collecting oral fluid samples in the home setting to determine seroprevalence of infections in a large-scale cohort of preschool-aged children
}

\author{
S. E. BARTINGTON, C. PECKHAM, D. BROWN, H. JOSHI and C. DEZATEUX
}

Epidemiology and Infection / Volume 137 / Issue 02 / February 2009, pp 211 - 218

DOI: 10.1017/S0950268808000927, Published online: 30 June 2008

Link to this article: http://journals.cambridge.org/abstract_S0950268808000927

How to cite this article:

S. E. BARTINGTON, C. PECKHAM, D. BROWN, H. JOSHI and C. DEZATEUX (2009). Feasibility of collecting oral fluid samples in the home setting to determine seroprevalence of infections in a large-scale cohort of preschool-aged children. Epidemiology and Infection, 137, pp 211-218 doi:10.1017/S0950268808000927

Request Permissions : $\underline{\text { Click here }}$ 


\title{
Feasibility of collecting oral fluid samples in the home setting to determine seroprevalence of infections in a large-scale cohort of preschool-aged children
}

\author{
S. E. BARTINGTON ${ }^{1 *}$, C. PECKHAM ${ }^{1}$, D. BROWN ${ }^{2}$, H. JOSHI ${ }^{3}$, C. DEZATEUX ${ }^{1}$ \\ and the Millennium Cohort Study Child Health Group ${ }^{\dagger}$ \\ ${ }^{1}$ MRC Centre of Epidemiology for Child Health, UCL Institute of Child Health, London, UK \\ ${ }^{2}$ Centre for Infections, Health Protection Agency, London, UK \\ ${ }^{3}$ Centre for Longitudinal Studies, Institute of Education, London UK
}

(Accepted 28 May 2008; first published online 30 June 2008)

\section{SUMMARY}

Oral fluid is a non-invasive biological sample, which can be returned by post, making it suitable for large-scale epidemiological studies in children. We report our experience of oral fluid collection from 14373 preschool-aged children in the UK Millennium Cohort Study. Samples were collected by mothers in the home setting following the guidance of trained interviewers, and posted to the laboratory. Samples were received from 11698 children $(81 \cdot 4 \%)$. Children whose mothers were of Black Caribbean ethnicity and who lived in non-English-speaking households were less likely to provide a sample, and those with a maternal history of asthma more likely to provide a sample [adjusted risk ratio $(95 \% \mathrm{CI}) 0.85(0.73-0.98), 0.87(0.77-0.98)$ and $1.03(1.00-1.05)$ respectively]. Collection of oral fluid samples is feasible and acceptable in large-scale child cohort studies. Formal interpreter support may be required to increase participation rates in surveys that collect biological samples from ethnic minorities.

Key words: Asthma, child cohort, hygiene hypothesis, Millennium Cohort Study, oral fluid.

\section{INTRODUCTION}

Objective measures of infection in young children are essential in epidemiological studies of acquisition of infections in early life, but blood sampling is not feasible in large-scale population-based studies at this age. However, as many common childhood infections are asymptomatic, or of non-specific symptomatology objective measures are needed. Oral fluid has been increasingly used as a minimally invasive alternative to blood in seroprevalence studies [1,2], and has the

\footnotetext{
* Author for correspondence: Miss S. E. Bartington, MRC Centre of Epidemiology for Child Health, UCL Institute of Child Health, 30 Guilford Street, London, UK. (Email: s.bartington@ich.ucl.ac.uk)

$\dagger$ Members of the Millennium Cohort Study Child Health Group are given in the Appendix.
}

potential to achieve higher population coverage. Effective methods for the collection, transport and processing of oral fluid samples have been developed and evaluated to ensure optimum sample quality [3-5]. There has been increasing interest in investigating the relationship between common childhood infections in very early childhood and later allergic and autoimmune disorders [6], but to date only limited experience of oral fluid collection to measure such infections objectively within large-scale cohort studies of preschool-aged children.

We report the feasibility of collecting oral fluid samples in the home setting from 3-year-old children in a large-scale, socially diverse and multi-ethnic cohort carried out as part of a prospective study investigating early childhood acquisition of infection and subsequent asthma and allergic disorders. 
Specifically we report the proportion of cohort members for whom a sample was received in the laboratory and the maternal and child factors associated with oral fluid sample receipt, including those relevant to allergic disorders or asthma.

\section{METHODS}

\section{Study population and design}

The Millennium Cohort Study (MCS) is a prospective study of the social, economic and health-related circumstances of British children born in the new century [7]. A stratified clustered survey design was employed to over-represent children living in disadvantaged areas, from ethnic minority groups and the smaller UK countries. The original cohort comprised 18818 children (18552 families), living in the United Kingdom at age 9 months when the first survey was conducted, representing a response rate of $72 \%$ at the first survey. A detailed description of the sampling design is provided elsewhere [8].

A second survey was conducted between September 2003 and January 2005 when cohort children were aged about 3 years [9]. At the second survey, 14630 $(80 \%)$ of 18296 mother-singleton infant pairs interviewed at the first survey were interviewed at home by social survey interviewers at a mean child age of 37.7 months (s.D. $=2 \cdot 5$ ). Interviewers were experienced in social and biomedical surveys but were not themselves clinically trained or qualified to collect biological samples. Translators were made available when neither a resident parent nor other household member aged $\geqslant 16$ years spoke English. At each interview, information was collected on a range of demographic, social, and health factors related to the child and their family.

We included 14373 singleton children with a natural mother as main survey respondent in the analyses reported here, for whom data from 12026 partner interviews were available, including 11676 natural fathers. Of these 14373 main respondents, 8993 were from England, 2201 from Wales, 1766 from Scotland and 1413 from Northern Ireland. Data from both surveys were obtained from the UK Data Archive, University of Essex [10, 11]. Fieldwork for the first and second MCS surveys received ethical approval from the South West and London Multi-Centre Research Ethics Committees, respectively [12]. The analyses presented required no further ethical committee approval.

\section{Invitation to participate}

Families, eligible for the second MCS survey, were sent a letter and a four-page study booklet a few days before the home interview. This included the 'Infections and Allergies Study' leaflet inviting them to participate in the oral fluid survey, and describing the hygiene hypothesis, the purpose of collecting oral fluid (referred to as 'saliva' for simplicity in this leaflet), and how it would be collected. The letter and leaflet were translated into ten languages, with translated versions sent to households identifying one of these languages as their main household language at the first survey [13]. All families in Wales were sent a study booklet in English and Welsh.

\section{Oral fluid collection}

Interviewers, informed about oral fluid collection methods using a purpose-made video presentation, explained to participating mothers how to collect a sample of oral fluid from their child using the Oracol oral fluid collection device (Malvern Medical Developments Ltd, Worcester, UK). This device was selected for its acceptability for use with children and its high oral fluid sample quality $[14,15]$. The absorbent foam swab included with this device was gently rubbed over the child's gums for 1 minute by the mother, or by the child if they wished, sealed in the supplied plastic tube, inserted into a larger tube labelled with a barcode denoting the cohort identification number and the date and time of sample, and posted using a pre-addressed reply-paid envelope to the laboratory. Mothers collecting the child's sample after the interview labelled and returned it by post using the same procedure. Upon receipt in the laboratory oral fluid samples were extracted from the sponge swab by agitation of the swab for $30 \mathrm{~s}$ in $1 \mathrm{ml}$ transport medium [PBS (pH 7.2) with $10 \%$ fetal calf serum, $0 \cdot 2 \%$ Tween-20, $0 \cdot 5 \%$ gentamicin, and $0 \cdot 2 \%$ fungizone] followed by centrifugation and division into four aliquots which were frozen at $-20^{\circ} \mathrm{C}$. Samples were tested for total immunoglobulin ( $\mathrm{IgG})$ content using a time-resolved fluorescent immunoassay.

\section{Explanatory variables}

We examined the following maternal social and demographic factors as potential predictors of response: maternal socio-economic status (based upon maternal occupation and categorized in accordance 
with the National Statistics Socioeconomic Classification) [16], ethnic group (categorized into eight groups in accordance with guidelines from the Office for National Statistics) [17], age at cohort child birth, level of education (obtained at the first survey, GCSEs at Grade C or above or no academic qualifications), smoking during pregnancy (yes/no); history of breastfeeding ( $<4$ months, $\geqslant 4$ months) and factors relevant to the allergic outcomes of interest for the hygiene hypothesis: maternal and paternal history of asthma, eczema, hayfever, or bronchitis (yes/no). All information for these variables was obtained at the first survey. We also examined the following variables collected at the second survey: cohort child sex and age at interview ( $<36$ months, 36-39 months, $>39$ months), maternal lone parent status, main household language (English, English and other language, or other language only) and cohort child history of asthma, eczema, hayfever or wheezing in the past 12 months, child day-care attendance (formal, informal, none), and total number of children in the household $(1,2-3, \geqslant 4)$.

\section{Statistical methods}

All analyses were weighted for non-response and survey design effect. Variables significantly associated with differences in oral fluid receipt were identified using the $F$ test, and analysed using a multivariable modified Poisson regression model for binary data [18] to report crude and adjusted risk ratios (aRRs). The robust Poisson model has been shown to provide more reliable prevalence estimates for a common outcome with binary data than a logistic regression model, using sandwich estimation to estimate robust standard errors [19]. We adjusted for child age and sex, and then used a stepped approach to examine associations with socio-economic and demographic factors, and other factors relevant to the hygiene hypothesis. Adjusted Wald tests were used to test for differences between regression coefficients. All analyses were conducted using Stata 9.2 with SVY commands [20].

\section{RESULTS}

Overall, oral fluid samples were received from 11698 $(81.4 \%)$ children, and this did not vary significantly by UK country (Table 1). Of 11698 samples, only 213 $(1.8 \%)$ did not contain any oral fluid detectable by measurement of total IgG content. The geometric
Table 1. Oral fluid sample receipt by social and demographic factors

\begin{tabular}{|c|c|c|c|}
\hline Measures & $\begin{array}{l}\text { Total } \\
N\end{array}$ & $\begin{array}{l}\text { Weighted } \\
\%\end{array}$ & $P$ value \\
\hline Country & & & $P=0.9$ \\
\hline England & 8993 & $81 \cdot 0$ & \\
\hline Wales & 2201 & $81 \cdot 3$ & \\
\hline Scotland & 1766 & $82 \cdot 3$ & \\
\hline Northern Ireland & 1413 & $81 \cdot 2$ & \\
\hline $\begin{array}{l}\text { Cohort child age at } \\
\text { interview (months) }\end{array}$ & & & $P<0.001$ \\
\hline$<36$ & 392 & $84 \cdot 5$ & \\
\hline $36-39$ & 12115 & $81 \cdot 6$ & \\
\hline$>39$ & 1866 & $76 \cdot 9$ & \\
\hline Cohort child sex & & & $P=0.08$ \\
\hline Male & 7343 & $80 \cdot 5$ & \\
\hline Female & 7030 & $81 \cdot 8$ & \\
\hline $\begin{array}{l}\text { Maternal socio-economic } \\
\text { status }\end{array}$ & & & $P=0.05$ \\
\hline $\begin{array}{l}\text { Professional and } \\
\text { managerial }\end{array}$ & 4072 & $81 \cdot 6$ & \\
\hline Intermediate occupations & 3812 & $81 \cdot 7$ & \\
\hline Routine and manual & 5025 & $81 \cdot 2$ & \\
\hline $\begin{array}{l}\text { Never worked/long-term } \\
\text { unemployed }\end{array}$ & 1288 & $77 \cdot 2$ & \\
\hline Maternal ethnicity & & & $P<0.001$ \\
\hline White & 12280 & $81 \cdot 8$ & \\
\hline Mixed & 127 & $74 \cdot 3$ & \\
\hline Indian & 363 & $80 \cdot 3$ & \\
\hline Pakistani & 646 & $77 \cdot 4$ & \\
\hline Bangladeshi & 246 & $75 \cdot 2$ & \\
\hline Black Caribbean & 175 & $69 \cdot 4$ & \\
\hline Black African & 235 & $71 \cdot 6$ & \\
\hline Other & 255 & $78 \cdot 3$ & \\
\hline $\begin{array}{l}\text { Maternal age at cohort } \\
\text { birth (years) }\end{array}$ & & & $P=0 \cdot 58$ \\
\hline $14-19$ & 1083 & $81 \cdot 5$ & \\
\hline $20-29$ & 6512 & $80 \cdot 7$ & \\
\hline $30-39$ & 6453 & $81 \cdot 7$ & \\
\hline$\geqslant 40$ & 318 & $82 \cdot 3$ & \\
\hline Maternal education & & & $P=0.61$ \\
\hline $\begin{array}{l}\text { Some academic } \\
\text { qualifications }\end{array}$ & 10366 & $81 \cdot 3$ & \\
\hline $\begin{array}{l}\text { No academic } \\
\text { qualifications }\end{array}$ & 3976 & $80 \cdot 8$ & \\
\hline Maternal lone parent status & & & $P=0 \cdot 12$ \\
\hline Lone parent & 2195 & $79 \cdot 8$ & \\
\hline Non-lone parent & 12178 & $81 \cdot 4$ & \\
\hline Household language & & & $P<0.001$ \\
\hline English only & 12255 & $81 \cdot 7$ & \\
\hline English and other & 1681 & $78 \cdot 8$ & \\
\hline Non-English speaking & 437 & $69 \cdot 7$ & \\
\hline
\end{tabular}

$N$, Weighted percentages.

Missing data: maternal socio-economic status (176), maternal ethnicity (46), maternal age at cohort child birth (7), maternal education (31). 
Table 2. Oral fluid sample receipt by factors associated with the hygiene hypothesis

\begin{tabular}{|c|c|c|c|}
\hline & Total $N$ & Weighted \% & $P$ value \\
\hline \multicolumn{4}{|l|}{ Maternal } \\
\hline $\begin{array}{l}\text { Smoking during } \\
\text { pregnancy }\end{array}$ & & & $P=0.76$ \\
\hline Yes & 4927 & $81 \cdot 3$ & \\
\hline No & 9386 & $81 \cdot 1$ & \\
\hline Asthma & & & $P=0 \cdot 01$ \\
\hline Yes & 2337 & $83 \cdot 1$ & \\
\hline No & 12022 & $80 \cdot 8$ & \\
\hline Eczema & & & $P=0.68$ \\
\hline Yes & 2495 & $82 \cdot 5$ & \\
\hline No & 11864 & $82 \cdot 0$ & \\
\hline Hayfever & & & $P=0 \cdot 37$ \\
\hline Yes & 3515 & $81 \cdot 7$ & \\
\hline No & 10846 & $81 \cdot 0$ & \\
\hline Bronchitis & & & $P=0.52$ \\
\hline Yes & 1123 & $81 \cdot 9$ & \\
\hline No & 13235 & $81 \cdot 1$ & \\
\hline \multicolumn{4}{|l|}{ Paternal* } \\
\hline Asthma & & & $P=0.25$ \\
\hline Yes & 1344 & $83 \cdot 3$ & \\
\hline No & 8602 & $81 \cdot 7$ & \\
\hline Eczema & & & $P=0.99$ \\
\hline Yes & 1066 & $81 \cdot 9$ & \\
\hline No & 8833 & $81 \cdot 9$ & \\
\hline Hayfever & & & $P=0.72$ \\
\hline Yes & 2330 & $82 \cdot 2$ & \\
\hline No & 7618 & $81 \cdot 8$ & \\
\hline Bronchitis & & & $P=0.33$ \\
\hline Yes & 702 & $83 \cdot 4$ & \\
\hline No & 9243 & $81 \cdot 8$ & \\
\hline \multicolumn{4}{|l|}{ Cohort child } \\
\hline $\begin{array}{l}\text { Asthma/wheezing } \\
\text { ever }\end{array}$ & & & $P=0.36$ \\
\hline Yes & 4709 & $81 \cdot 7$ & \\
\hline No & 9604 & $80 \cdot 9$ & \\
\hline Wheezing in past & & & $P=0.65$ \\
\hline \multicolumn{4}{|l|}{12 months } \\
\hline Yes & 2859 & $80 \cdot 8$ & \\
\hline No & 11512 & $81 \cdot 3$ & \\
\hline Ever eczema/hayfever & & & $P=0.64$ \\
\hline Yes & 5136 & $81 \cdot 0$ & \\
\hline No & 9115 & $81 \cdot 4$ & \\
\hline Breastfed & & & $P=0.49$ \\
\hline$\geqslant 4$ months & 3742 & $81 \cdot 6$ & \\
\hline$<4$ months & 10616 & $81 \cdot 0$ & \\
\hline Day-care attendance & & & $P=0.68$ \\
\hline None & 10636 & $81 \cdot 1$ & \\
\hline Informal & 2145 & $81 \cdot 8$ & \\
\hline Formal & 1592 & $80 \cdot 7$ & \\
\hline Children in household & & & $P=0.62$ \\
\hline 1 & 3565 & $81 \cdot 4$ & \\
\hline $2-3$ & 9294 & $81 \cdot 4$ & \\
\hline$\geqslant 4$ & 1514 & $80 \cdot 2$ & \\
\hline
\end{tabular}

$N$, Weighted percentages.

* $N=11676$. mean of total IgG was 2.07 AU/ml [95\% CI (confidence interval) $2 \cdot 02-2 \cdot 11]$. In univariable analyses, samples were less likely to be received from older children, boys, children whose mothers had never worked or were unemployed, whose mothers were of non-white ethnicity, or who lived in non-Englishspeaking households (Table 1). Among those variables relevant to the hygiene hypothesis, none were significant apart from a maternal history of asthma: samples were received from $83 \cdot 1 \%$ and $80.8 \%$ of children of mothers with and without a history of asthma, respectively (Table 2).

These associations remained after adjustment for child age and sex. Further adjustment using a stepped approach did not attenuate associations significantly with the exception of associations with maternal Pakistani and Black African ethnicity which attenuated after adjustment for maternal socio-economic status, and with maternal unemployment which attenuated after adjustment for maternal ethnicity. After adjustment for all factors, children of Black Caribbean mothers remained significantly less likely to provide a sample (aRR 0.85, 95\% CI 0.73-0.98) as did children living in non-English-speaking households (aRR 0.87, 95\% CI 0.77-0.98) (Table 3). Conversely, children of mothers with a history of asthma were slightly but significantly more likely to provide a sample (aRR 1·03, 95\% CI 1·00-1·05).

\section{DISCUSSION}

This is to our knowledge the first large-scale child cohort study in which oral fluid has been collected by the mother from preschool-aged children in the home setting, with an explanation from a trained interviewer. The high response rate achieved suggests that this methodology is feasible and acceptable, with $98.2 \%$ of returned oral fluid devices having $\operatorname{IgG}$ detected on the foam swab. We have identified social and ethnic factors associated with a mother's decision

\section{(Table 2 notes continued)}

Missing data: maternal smoking during pregnancy (60), maternal asthma (14), maternal eczema (14), maternal hayfever (12), maternal bronchitis (15), paternal asthma (1730), paternal eczema (1727), paternal hayfever (1728), paternal bronchitis (1731), breastfeeding history (15), cohort child asthma/wheezing (60), cohort child asthma or wheezing in past 12 months (2) cohort child eczema/ hayfever (122). 
Table 3. Factors associated with oral fluid sample receipt

\begin{tabular}{|c|c|c|c|}
\hline Measures & $\%(N)$ & Crude RR (95\% CI) & $\begin{array}{l}\text { Fully adjusted aRR } \\
(95 \% \mathrm{CI}) \dagger\end{array}$ \\
\hline \multicolumn{4}{|l|}{ Maternal socio-economic status } \\
\hline Professional and managerial & $30 \cdot 3(4072)$ & $1 \cdot 00(0 \cdot 98-1 \cdot 03)$ & $1 \cdot 00(0 \cdot 98-1 \cdot 02)$ \\
\hline Intermediate occupations & $27 \cdot 9(3812)$ & $1 \cdot 01(0 \cdot 98-1 \cdot 03)$ & $1 \cdot 01(0 \cdot 98-1 \cdot 03)$ \\
\hline Routine and manual & $34 \cdot 8(5025)$ & 1 & 1 \\
\hline $\begin{array}{l}\text { Never worked/long-term } \\
\text { unemployed }\end{array}$ & $7 \cdot 1(1288)$ & $0.95(0.91-0.99)^{*}$ & $0.98(0 \cdot 93-1 \cdot 03)$ \\
\hline \multicolumn{4}{|l|}{ Maternal ethnicity } \\
\hline White & $88 \cdot 8(12280)$ & 1 & 1 \\
\hline Mixed & $0.9(127)$ & $0 \cdot 91(0 \cdot 81-1 \cdot 02)$ & $0 \cdot 92(0 \cdot 82-1 \cdot 03)$ \\
\hline Indian & $1 \cdot 9(363)$ & $0 \cdot 98(0 \cdot 92-1 \cdot 04)$ & $1 \cdot 03(0 \cdot 95-1 \cdot 11)$ \\
\hline Pakistani & $3 \cdot 2(646)$ & $0.95(0.90-0.99)^{*}$ & $1 \cdot 00(0 \cdot 94-1 \cdot 07)$ \\
\hline Bangladeshi & $1 \cdot 0(246)$ & $0 \cdot 92(0 \cdot 84-1 \cdot 01)$ & $0 \cdot 98(0 \cdot 87-1 \cdot 10)$ \\
\hline Black Caribbean & $1 \cdot 1(175)$ & $0.85(0.73-0.98)^{*}$ & $0.85(0.73-0.98)^{*}$ \\
\hline Black African & $1 \cdot 5(235)$ & $0.88(0.77-0.99)^{*}$ & $0 \cdot 94(0 \cdot 83-1 \cdot 06)$ \\
\hline Other & $1 \cdot 6(255)$ & $0 \cdot 96(0 \cdot 87-1 \cdot 05)$ & $1 \cdot 01(0 \cdot 93-1 \cdot 11)$ \\
\hline \multicolumn{4}{|l|}{ Household language } \\
\hline English only & $89 \cdot 4(12255)$ & 1 & 1 \\
\hline English and other & $8 \cdot 4(1681)$ & $0 \cdot 96(0 \cdot 93-1 \cdot 00)$ & $0 \cdot 98(0 \cdot 93-1 \cdot 03)$ \\
\hline Non-English speaking & $2 \cdot 2(437)$ & $0.85(0.76-0.95)^{*}$ & $0.87(0.77-0.98)^{*}$ \\
\hline \multicolumn{4}{|l|}{ Maternal asthma } \\
\hline Yes & $16 \cdot 8(2337)$ & $1 \cdot 03(1 \cdot 01-1 \cdot 05)^{*}$ & $1 \cdot 03(1 \cdot 00-1 \cdot 05)^{*}$ \\
\hline No & $83 \cdot 2(12022)$ & 1 & 1 \\
\hline
\end{tabular}

$\mathrm{RR}$, Risk ratio; aRR, adjusted risk ratio; CI, confidence interval.

Weighted percentages $(N)$.

$\dagger$ Adjusted for age and sex of cohort child, maternal socio-economic status, ethnic group, household language and maternal asthma.

* $P \leqslant 0 \cdot 05$.

to collect oral fluid from her child, with samples less likely to be received from children of mothers from Black Caribbean ethnic groups or from those living in non-English-speaking households. Although children of mothers with a history of asthma were statistically more likely to provide a sample, the effect was small and there were no associations with other measures of allergy and asthma in the child or parent.

Strengths of our study include the size, representativeness and diversity of the cohort, as well as the rich range of social and demographic information available on cohort families and children. This has enabled comprehensive examination of factors associated with oral fluid sample provision in multi-ethnic and socially diverse population-based cohort studies and provides novel insights relevant to future studies in this age group. Unfortunately a precise record of who declined to provide a sample (mother, child or both), whether the mother or child took the sample, or whether the interviewer was present at sample collection was not retained.

Although a number of large-scale seroprevalence studies based on oral fluid samples have been carried out by post previously, these have included a wide age range of participants and provide only limited information regarding factors associated with response in young children. A recent postal oral fluid study of 2448 potential participants aged 20-39 years in Canada, reported a response rate of $59 \%$ [21]. In England and Wales a postal seroprevalence survey of adults and children conducted by the Health Protection Agency reported an overall response of $40 \%$, and this was lower amongst men and ethnic minorities [22]. A higher response rate of $60 \%$ was attained from 962 households surveyed in Ireland [23]. In these postal studies participants were contacted only by letter, with a request for self-collection with no interviewer present. In our study, mothers had already agreed to completion of the survey 
questionnaire when approached about the oral fluid sample and an interviewer explained how to collect samples. This may account for the higher response achieved in our study compared to that reported in other published postal surveys.

Higher participation rates have been reported in smaller studies where a nurse or a health-care professional has collected the sample, although only limited information is available by age group. For example, 84/91 (92\%) parents agreed to their child taking part in a study to examine the feasibility of using oral fluids for hepatitis $\mathrm{C}$ virus testing of 3- to 10-year-olds; $70 / 84(83 \%)$ of the children whose parents had given consent also agreed to take part [24]. In this small study, older children were more likely to take part, but participation did not vary by sex of child, or by area-level deprivation. In contrast, within the narrow age range represented in our study, younger children were more likely to provide a sample. Similar response rates were reported from a study of 11-year-olds in Scottish primary schools where $554 / 720(77 \%)$ of children provided a sample [25]. A recently published case-control study in East Anglia recruited preschool-aged children but did not report participation rates [26]. Unfortunately the precise method of sample collection was not reported in either of these studies.

There was only limited evidence that a history of asthma or allergic disease in the child or family influenced participation, with a maternal history of asthma associated with a small but statistically significant increase in sample receipt. In previous studies of parental participation in paediatric research, parents have also cited an opportunity to learn more about their child's clinical illness and a willingness to contribute to medical knowledge as reasons for taking part, but these studies have been carried out in clinical rather than population-based settings [27, 28].

Although, overall, response was high in our study, our findings suggest that despite provision of translated study information sheets and use of family members or professional interpreter support, some barriers to participation remain for mothers living in non-English-speaking households. Other factors in the fieldwork design may be relevant, including the provision of written information in languages that may be spoken but not necessarily read in a nonEnglish-speaking household [29]. Hunt \& Bhopal have highlighted the need for greater awareness of cultural differences to increase participation in multi-ethnic research studies, while others have examined the need for further research to identify the barriers and facilitators for involvement of different population groups [30-32].

We found that children of Black Caribbean mothers were less likely to provide oral fluid, and this was independent of home language and socioeconomic status. We were unable to identify any UK studies specifically exploring ethnic variation in provision of non-invasive biological samples for research, although there is a growing literature examining non-participation in clinical trials and observational studies [33-36]. Under-representation of Black African American ethnic minorities in clinical medical research has been consistently reported from the United States $[37,38]$. While this has been attributed to factors such as a lower level of trust in medical research [39], others have suggested that under-representation of ethnic minorities in health research may reflect failure to approach these groups rather than their refusal to participate [40]. Our study was not, however, carried out in a health-care setting, all cohort families irrespective of ethnic background, were invited to participate and observed ethnic differences were independent of socio-economic factors. While qualitative research might be helpful to identify other barriers to participation, overall the response rates achieved are high and future analyses of seroprevalence will adjust for non-response.

In conclusion, we have demonstrated that a high proportion of mothers and their preschool-aged children participating in a UK-wide cohort are willing to provide an oral fluid specimen in the home setting following verbal explanation by an interviewer supplemented by written information. While lower among certain ethnic groups and non-English-speaking households, overall response was high indicating that oral fluid is a feasible and acceptable biological sample for use in population-based seroprevalence studies in this age group. Formal interpreter support may be required to increase participation rates in surveys that collect biological samples from ethnic minorities.

\section{APPENDIX}

Members of the Millennium Cohort Study Child Health Group: Helen Bedford, Tim Cole, Phillippa Cumberland, Lucy Griffiths, Summer Sherburne Hawkins, Catherine Law, Anna Pearce, Jugnoo Rahi, Carly Rich. 


\section{ACKNOWLEDGEMENTS}

We thank the Millennium Cohort families for their cooperation; Jon Johnson and the Millennium Cohort Study team at the Centre for Longitudinal Studies, Institute of Education for clarifying the variables at the second survey; Jim Gray, Rebecca Sedwell and Farah Aladin at the Centre for Infections at the Health Protection Agency for providing data. We also acknowledge the contribution of the late Professor Neville Butler who was a member of the MCS Child Health Group. This work was undertaken at GOSH/UCL Institute of Child Health which received a proportion of funding from the Department of Health's NIHR Biomedical Research Centres funding scheme. This study was funded by the Sir Siegmund Warburg Voluntary Settlement. Suzanne Bartington was supported by a Medical Research Council Doctoral Studentship.

\section{DECLARATION OF INTEREST}

None.

\section{REFERENCES}

1. George JR, Fitchen JH. Future applications of oral fluid specimen technology. American Journal of Medicine 1997; 102: 21-25.

2. Nokes DJ, et al. Has oral fluid the potential to replace serum for the evaluation of population immunity levels? A study of measles, rubella and hepatitis B in rural Ethiopia. Bulletin of the World Health Organisation 2001; 79: 588-595.

3. McKie A, Vyse A, Maple C. Novel methods for the detection of microbial antibodies in oral fluid. Lancet Infectious Diseases 2002; 2: 18-24.

4. Morris MC, et al. Oral fluid collection by post - a pilot study of two approaches. Public Health 2002; 116: 113-119.

5. Morris MC, et al. Stability of total and rubella-specific IgG in oral fluid samples: the effect of time and temperature. Journal of Immunological Methods 2002; 266: 111-116.

6. von Mutius E. Allergies, infections and the hygiene hypothesis - the epidemiological evidence. Immunobiology 2007; 212: 433-439.

7. Smith K, Joshi H. The Millennium Cohort Study. Population Trends 2002; 107: 30-34.

8. Plewis I. Millennium Cohort Study: Technical Report on Sampling, 4th edn. London: Institute of Education, University of London, 2007 (http://www.cls.ioe.ac.uk/ studies.asp?section $=00010002000100050004$ ). Accessed 24 July 2007.

9. Plewis I, Ketende S. Millennium Cohort Study: Technical Report on Response, 1st edn. London: Institute of Education, University of London, 2006. (http://www.cls.ioe.ac.uk/studies.asp?section $=0001000$ 2000100040006). Accessed 24 July 2007.

10. UK Data Archive. Millennium Cohort Study First Survey (http://www.dataarchive.ac.uk/findingData/ snDescription.asp?sn = 4683). Accessed 24 July 2007.

11. UK Data Archive. Millennium Cohort Study Second Survey (http://www.dataarchive.ac.uk/findingData/ snDescription.asp?sn=5350). Accessed 24 July 2007.

12. Hansen K. Millennium Cohort Study First and Second Surveys: A Guide to the Datasets, 1st edn. London: Institute of Education, University of London, 2006.

13. GfK NOP Social Research. Millennium Cohort Study-Sweep 2. Technical Report on Fieldwork (http://www.cls.ioe.ac.uk/studies.asp?section $=0001000$ 2000100040006). Accessed 24 July 2007.

14. Vyse AJ, Cohen BJ, Ramsay ME. A comparison of oral fluid collection devices for use in the surveillance of virus diseases in children. Public Health 2001; 115: 201-207.

15. Nokes DJ, et al. An evaluation of oral-fluid collection devices for the determination of rubella antibody status in a rural Ethiopian community. Transactions of the Royal Society of Tropical Medicine and Hygiene 1998; 92: 679-685.

16. Rose D, Pevalin DA. A Researchers Guide to the National Statistics Socioeconomic Classification. London: Sage Publications, 2003.

17. Office for National Statistics. Ethnic group statistics. A guide for the collection and classification of ethnicity data. Technical report (http://www.statistics.gov.uk/ about/ethnic_group_statistics/). Accessed 30 July 2007.

18. Zou G. A modified Poisson regression approach to prospective studies with binary data. American Journal of Epidemiology 2004; 159: 702-706.

19. Petersen MR, Deddens JA. A comparison of two methods for estimating prevalence ratios. BMC Medical Research Methodology 2008; 8: 9.

20. Stata Corporation. Survey Data Reference Manual Release 9. Stata Press, 2005.

21. Ochnio JJ, et al. Participant-collected, mail-delivered oral fluid specimens can replace traditional serosurveys: a demonstration-of-feasibility survey of hepatitis A virus-specific antibodies in adults. Canadian Journal of Public Health 2007; 98: 37-40.

22. Morris-Cunnington MC, et al. A population-based seroprevalence study of Hepatitis A virus using oral fluid in England and Wales. American Journal of Epidemiology 2004; 159: 786-794.

23. O'Connell T, et al. Oral fluid collection by post for viral antibody testing. International Journal of Epidemiology 2001; 30: 298-301.

24. Chatzipantazi $\mathbf{P}$, et al. The feasibility and acceptability of collecting oral fluid from healthy children for antiHCV testing. Archives of Disease in Childhood 2004; 89: 185-187.

25. Crowcroft NS, et al. Epidemiology of Epstein-Barr virus infection in pre-adolescent children: application of a new salivary method in Edinburgh, Scotland. Journal of Epidemiology and Community Health 1998; 52: 101-104. 
26. Gibbs S, et al. Atopic dermatitis and the hygiene hypothesis. International Journal of Epidemiology 2004; 33: 199-207.

27. Rothmier JD, Lasley MV, Shapiro G. Factors influencing parental consent in pediatric clinical research. Pediatrics 2003; 111; 1037-1041.

28. Tait A, Voepel-Lewis T, Malviya S. Participation of children in clinical research: factors that influence a parent's decision to consent. Anesthesiology 2003; 99: 819-825.

29. Sabri AA, Qayyum MA. Increasing the participation: another factor. PLoS Med 2005; 3: e 250 .

30. Hunt SM, Bhopal R. Self report in clinical and epidemiological studies with non-English speakers, the challenge of language and culture. Journal of Epidemiology and Community Health 2004; 58: 618-622.

31. Hunt S, Bhopal R. Self reports in research with nonEnglish speakers. British Medical Journal 2003; 327 : 352-353.

32. Bartlett C, et al. The causes and effects of sociodemographic exclusions from clinical trials. Health Technology Assessment 2005; 9: 1-152.

33. Hussain-Gambles M, Atkin K, Leese B. Why ethnic minority groups are under-represented in clinical trials: a review of the literature. Health and Social Care in the Community 2004; 12: 382-388.

34. Hussain-Gambles M, et al. Involving South Asian patients in clinical trials. Health Technology Assessment 2004; 42: 1-109.

35. Mason S, et al. Representation of South Asian people in randomised clinical trials: analysis of trials' data. British Medical Journal 2003; 326: 1244-1245.

36. Chan H, Moriarty K. Are ethnic minorities excluded from clinical research? Bulletin of Medical Ethics. 2005; 211: 22-24.

37. Lamvu G, et al. Racial differences among reasons for participating in research of pregnancy outcomes: The right from the start experience Gender Medicine 2005; 2: 166-173.

38. Crider KS, et al. Racial and ethnic disparity in participation in DNA collection at the Atlanta Site of the National Birth Defects Prevention Study. American Journal of Epidemiology 2006; 164: 805-812.

39. Shavers VL, et al. Racial differences in factors that influence the willingness to participate in medical research studies. Annals of Epidemiology 2002; 12: 248-256.

40. Sheikh A. Why are ethnic minorities under-represented in US research studies? PLoS Med 2005; 3: e49. 